\title{
Características de los Contadores Públicos involucrados en temas de fraude en Colombia, desde la perspectiva de género, entre el año 2012 y el 2017.
}

\author{
Damar Camilo González Cubillos ${ }^{1}$ \\ Daniela Ramírez Vargas ${ }^{2}$
}

\section{Resumen.}

Durante décadas, algunos profesionales en contabilidad se han visto implicados en escándalos de estafas, desviaciones de recursos, sobornos y actos deshonestos en los que se cree que la mayoría de involucrados son hombres, por esta razón, se busca identificar la relación entre el género de un profesional y el delito cometido, a través del establecimiento de las características que tienen en común los Contadores Públicos que han cometido acciones fraudulentas. Lo anterior, a partir del análisis de las sanciones impuestas por un ente disciplinario entre los años 2012-2017 ${ }^{3}$, el estudio de casos reales de corrupción en Colombia y la revisión bibliográfica de fuentes similares, que permitieron concluir que los profesionales contables del género masculino están más involucrados en actos corruptos pese a que son minoría, en relación con el total de contadores activos.

Palabras clave. Género, fraude, contabilidad, sanciones, Contadores Públicos.

\section{Introducción.}

En la última década, Colombia se ha visto envuelta en una serie de escándalos, de fraude y corrupción. Casos como el carrusel de contratación del Grupo Nule, las estafas de Interbolsa, o el más reciente de Odebrecht; tienen en común que:

Han puesto en riesgo la confianza pública y se han caracterizado por implicar a empleados de la alta gerencia, por la existencia de vacíos éticos y legales, y en general, por enmarcarse en los dos tipos de fraude: por malversación de activos y manipulación de información financiera. (Ochoa, Zamarra, \& Castaño, 2012, pág. 3)

Los anteriores casos mencionados, son el reflejo de "una falta de cultura de control y la ausencia de valores morales, originada por los nuevos patrones económicos y culturales que convergieron a partir de la década de los 80" (Aguilar, 1996, pág. 195). Es decir, la idea del dinero fácil que dejó el narcotráfico ha repercutido en el manejo de las empresas, desde su auge hasta el día de hoy. Así mismo, "los pocos casos que trascienden a los medios de comunicación constituyen

\footnotetext{
Este documento es producto de la opción de grado: Trabajo de grado.

1 Estudiante de décimo semestre de Contaduría Pública en la Universidad Santo Tomás, sede Bogotá. damargonzalez@usantotomas.edu.co

2 Estudiante de décimo semestre de Contaduría Pública en la Universidad Santo Tomás, sede Bogotá. daniela.ramirezv@usantotomas.edu.co

3 El periodo de estudio se realizó entre los años 2012-2017 debido a que la lista de sancionados de la Junta Central de contadores (tomada en 2017 cuando se inició el estudio) que es base fundamental de la investigación, muestra únicamente los últimos 5 años de contadores públicos sancionados.
} 
verdaderos escándalos, tanto por los montos comprometidos como por la categoría de algunos implicados" (Aguilar, 1996, pág. 196); lo que lleva a que queden en el anonimato muchos otros sucesos.

Dicha problemática, se ha extendido hasta instancias inimaginables; de seguir así, Colombia no avanzará ni económica ni culturalmente; se abrirá mucho más la brecha social, originando que la pobreza extrema se propague hasta poblaciones vulnerables y por supuesto, que los ricos lo sean cada vez más. Esto dejaría a entrever, que se reducirán las probabilidades de garantizar los derechos fundamentales para toda la población y los casos de corrupción y fraude se incrementarán, como una alternativa de supervivencia (Londoño, 1997).

Para mitigar el riesgo de fraude y corrupción es necesario promover los principios éticos y morales, como una cultura de cambio. Por otra parte, es necesario indagar, en qué casos se han visto implicados más hombres que mujeres, y cuestionarse, si esto es determinante a la hora de evaluar la ética profesional de un contador público y las razones que han llevado a que esto suceda. Es por ello, que se deben analizar las características de los Contadores Públicos involucrados en temas de fraude contable en Colombia, desde la perspectiva de género, a partir de las sanciones impuestas por la Junta Central de Contadores ${ }^{4}$ entre el año 2012 y el 2017.

Asimismo, la investigación propuesta, mediante la consulta de artículos científicos en diferentes bases de datos, referentes a los temas de ética profesional y género; y al análisis de las sanciones impuestas por la Junta Central de Contadores, pretende evidenciar algunas de las razones que incitaron a los Contadores Públicos a involucrarse en los escándalos de fraude y corrupción que se presenciaron entre el año 2012 y 2017; y de igual manera, se busca comprobar si el género es un factor determinante al momento de evaluar la ética de un profesional.

\footnotetext{
${ }^{4}$ De acuerdo con el artículo 20 de la Ley 43 de 1990, son funciones de la JJC;

1. Ejercer la inspección y vigilancia, para garantizar que la Contaduría Pública sólo sea ejercida por Contador Público debidamente inscritos y que quienes ejerzan la profesión de Contador Público, lo haga de conformidad con las normas legales, sancionando en los términos de la ley, a quienes violen tales disposiciones.

2. Efectuar la inscripción de Contadores Públicos, suspenderla, o cancelarla cuando haya lugar a ello, así mismo llevar su registro.

3. Expedir, a costa del interesado, la tarjeta profesional y su reglamentación, las certificaciones que legalmente esté facultada para expedir.

4. Denunciar ante autoridades competentes a quien se identifique y firme como Contador Público sin estar inscrito como tal.

5. En general hacer que se cumplan las normas sobre ética profesional.

6. Establecer Juntas Seccionales y delegar en ellas las funciones señaladas en los numerales 4 y 5 de este artículo y las demás que juzgue conveniente para facilitar a los interesados que residan fuera de la capital de la República el cumplimiento de los respectivos requisitos.

7. Darse su propio reglamento de funcionamiento interno.

8. Las demás que le confieran las leyes. (Junta Central de Contadores, 2018)
} 
Lo anterior, llevará a conocer la cantidad de Contadores Públicos involucrados en corrupción y las características similares que se evidencian en cada uno, con el fin de examinar dichas pautas en casos concretos. Para lograr esto, se pretende identificar las causas y efectos de las sanciones aplicadas por la Junta Central de Contadores entre 2012-2017, a partir de un análisis de casos , teniendo como base la información adquirida en la base de datos de la JCC. Además, se determinaron los patrones recurrentes en los casos más relevantes de fraude en Colombia.

\section{La corrupción como el "cáncer" de Colombia.}

En primera medida, una de las formas más comunes de delinquir que se encuentra en la profesión contable es el fraude a los Estados Financieros; definido básicamente como "un acto intencional perpetrado por la Gerencia, o personal de una empresa, con fines ilícitos para buscar una ventaja personal o para un grupo determinado" (Mendoza, 2009, pág. 227). El fraude contable es un tema que ha tomado mucha fuerza en los diferentes ámbitos de la sociedad, de tal forma que son varios los casos que han salido a la luz pública reflejando que hay un gran vacío ético en algunos de los profesionales que se ven envueltos en estos escándalos; por esta razón, "estudiar y analizar el fraude es una necesidad urgente en Colombia para contribuir a que las pérdidas por este delito se reduzcan a niveles tolerables" (Aguilar, 1996, pág. 195). Frente a lo anterior los profesionales de la Contaduría Pública son los principales implicados; por lo que se crea la necesidad de determinar si hay algún factor que incida en el comportamiento de los Contadores y si este puede estar relacionado con el género de las personas.

Además, la corrupción es una problemática que afecta el país en todos los ámbitos, esta tiene muchas causas y consecuencias, por ejemplo, "la incertidumbre que genera la corrupción por entenebrecer la competencia leal, con sentido humano y social y con proyección de crecimiento, acrecienta costos, resquebraja iniciativas, ahuyenta inversores y distorsiona la política de emprendimiento" (Gómez, 2011, pág. 226). En ese orden de ideas, para (Caruso, 2009) "El fenómeno de la corrupción se caracteriza por los siguientes elementos: la violación de un deber posicional, un sistema normativo de referencia y la expectativa de obtener un beneficio indebido" (Pág. 145).

Es importante resaltar, que Colombia a través de los años ha enfrentado bastantes problemas de corrupción, este es un tema muy importante para la sociedad y debido a esto se han dispuesto algunas medidas regulatorias, "Colombia, país de leyes por excelencia, cuenta con diferentes instrumentos normativos para combatir la corrupción; entre ellos la Ley 1474 de 2011, mejor conocida como Estatuto Anticorrupción" (Gómez, 2014, pág. 51). También, a raíz de todas las consecuencias que trae consigo el fraude contable se han ido implementado políticas en las empresas para fortalecer la ética contable. Por lo cual, Peña y Bastidas (2007) estudian la incidencia que tiene el tema de ética profesional en las Normas Internacionales de Información Financiera, siendo este un marco de referencia para que los Contadores Públicos universalmente lleven el mismo código de ética (IFAC,2018) y que de esta manera se genere una cultura entre las organizaciones para garantizar la veracidad de la contabilidad de las compañías. 
Además, se hace importante:

Crear una cultura del no fraude, en donde los empleados de las organizaciones sean conscientes de las pérdidas y de lo malo que puede llegar a ser esto tanto para ellos como para su empresa y constituir un área ética se hace primordial, un área que enseñe a sus empleados la responsabilidad y el sentido de pertenencia para con su empresa. (Arboleda, 2015, pág. 26)

Si bien todas las contribuciones han ayudado a determinar las maneras en que se puede dar el fraude y así detectarlo más fácilmente, es importante seguir indagando desde diferentes perspectivas para que cada vez sean menos los casos y se tengan organizaciones más transparentes.

\section{La mujer y su aporte en los inicios de la contabilidad.}

En primera instancia, es importante aclarar que "la perspectiva de género es un enfoque teórico procedente de las teorías feministas, cuyo eje principal es el análisis de las desigualdades de sexo" (Ariño, et al., 2011, pág 146). Por lo tanto, para el desarrollo de la investigación se definirá género como "el que aglutina al conjunto de relaciones socioeconómicas y culturales entre personas de distinto sexo. El sexo viene determinado biológicamente, mientras que el género es un concepto socioeconómico y, por tanto, una creación de las sociedades humanas" (Calatrava, 2002, pág. 73).

Ahora bien, si se analiza la mujer a través de un enfoque histórico, ha estado delegada a cumplir las funciones básicas del hogar y la familia. Durante muchos años, el rol que desempeñaba era limitado y no se le permitía ninguna actividad diferente. Sin embargo, profesiones derivadas de la Economía, tales como la Contaduría o la Administración, tuvieron sus raíces precisamente en esas actividades cotidianas, de ahí que, "los registros contables, que reflejan hechos económicos encuadrados en unas circunstancias sociales, económicas y políticas concretas y a menudo cambiantes, han estado ligados a lo largo de la historia a las actividades domésticas" (Méndez, 2010, pág. 91). Por lo tanto, al observarlo desde esa perspectiva, las mujeres han tenido más habilidades para el quehacer contable, dado que manejaban el dinero familiar tan minuciosamente, que, sin saber, relacionaron conceptos como presupuestos, finanzas, costo - beneficio, ahorro, inversión, ingresos y gastos.

Cabe señalar, que "la incorporación de las mujeres al mundo profesional no ha sido fácil ni rápida, y en la contabilidad, como en otros campos, se ha debido en buena parte a los cambios socioeconómicos producidos en los dos últimos siglos" (Méndez, 2010, pág. 97). Es decir, que, a causa de una lucha constante, por el reconocimiento y el trato equitativo, se introdujo el concepto de Feminismo, "logrando transformaciones importantes en las condiciones de desigualdad existentes; dichos cambios fueron el resultado de leyes e instituciones defensoras de los derechos de las mujeres y contribuyeron a garantizar la igualdad de género en diferentes aspectos" (Acosta, Patiño, Valero, \& Diaz, 2015, pág. 38). 
Como resultado de esta lucha, la Constitución Política de 1991, "promovió el acceso a la mujer al sistema educativo y al mercado laboral" (Acosta, Patiño, Valero \& Díaz, 2015, pág. 62). Sin embargo, aún se ve discriminación de género en la sociedad, por tal motivo existen "movimientos revolucionarios que en algunas ocasiones se encaminan hacia un feminismo radical con un impacto plenamente social" (Acosta, Patiño, Valero \& Díaz, 2015, pág. 67). Dentro de ese contexto, dichos cambios han presionado para que las diferentes disciplinas vayan adaptándose a las exigencias del entorno; y la Contaduría Pública no podía ser la excepción. Hablando únicamente de Colombia, las variaciones en ámbitos culturales, sociales y políticos, procedentes de la consolidación del narcotráfico y el afán por el dinero fácil, lograron modificar la percepción de responsabilidad social inherente en esta ocupación (Álvarez, 2002).

\section{Metodología desarrollada.}

Para el desarrollo de la investigación, se utilizó una metodología cualitativa, a partir del análisis de la base de datos creada por la Junta Central de Contadores con las siguientes variables: género, sanción impuesta y el motivo que condujo a dicha penalidad, comprendidas entre los años 20122017. Adicionalmente, se realizó una revisión documental, que incluyó los temas de género y fraude para complementar la caracterización de los profesionales de la contaduría pública involucrados en fraudes. De igual manera, se realizó un estudio de tipo explicativo, para analizar detalladamente algunos casos reales, en los que se pueden evidenciar los patrones de comportamiento de los Contadores Públicos implicados, independientemente de su género. Finalmente, se evaluó toda la información recolectada para conocer con exactitud las características de los hombres y mujeres implicados en actos fraudulentos en el periodo objeto de estudio.

En el desarrollo de la investigación, se efectuaron las siguientes fases:

1. Recolección de información: Recopilación de bibliografía referente a temas de fraude, género y ética profesional, en los que se evidencian las características culturales y comportamentales de los Contadores Públicos implicados en temas de fraude. Esta recolección se hizo por medio de buscadores como: Redalyc y Google Académico en su mayoría; sin embargo, se agregaron documentos de otras fuentes. Inicialmente se tomaron documentos con fecha entre 2012-2017, pero también se tuvo la posibilidad de analizar algunos documentos fuera de estos años. De estos artículos se identificó cualquier relación que hubo entre género y fraude, implícita o explícitamente.

2. Análisis de información cualitativa: Con base en el listado de Contadores Públicos que han sido sancionados por la Junta Central de Contadores entre los años 2012-2017, se clasificaron por: tipo de sanción (amonestación, multa, suspensión y cancelación) y género. Posteriormente, en cuanto a las causas se evidencio sí el comportamiento fue grave o leve y si existió dolo o culpa, teniendo el primer resultado de la investigación. 
3. Construcción del documento: teérica: Unificación de los datos concretos ya recolectados, identificando algunas de las características de los contadores públicos involucrados en fraudes para lo cual se elaboró una estadística con la clasificación que se mencionó anteriormente del listado de la Junta Central de Contadores, con el fin de mostrar si los hombres o las mujeres están involucrados en fraudes. Ya con los resultados obtenidos, se evidenciaron qué factores se encuentran también en algunos de los casos más relevantes de fraude en Colombia, comprobando cuáles de estos son determinantes a la hora de cometer fraude haciendo énfasis en el género.

\section{Resultados:}

Partiendo del listado de contadores sancionados por la JCC, y con el fin de obtener un análisis claro en los resultados, se debe tener en cuenta el total de los contadores públicos hombres y mujeres activos a 2018, tal como se evidencia a continuación:

\section{Total de Contadores Públicos Activos:}

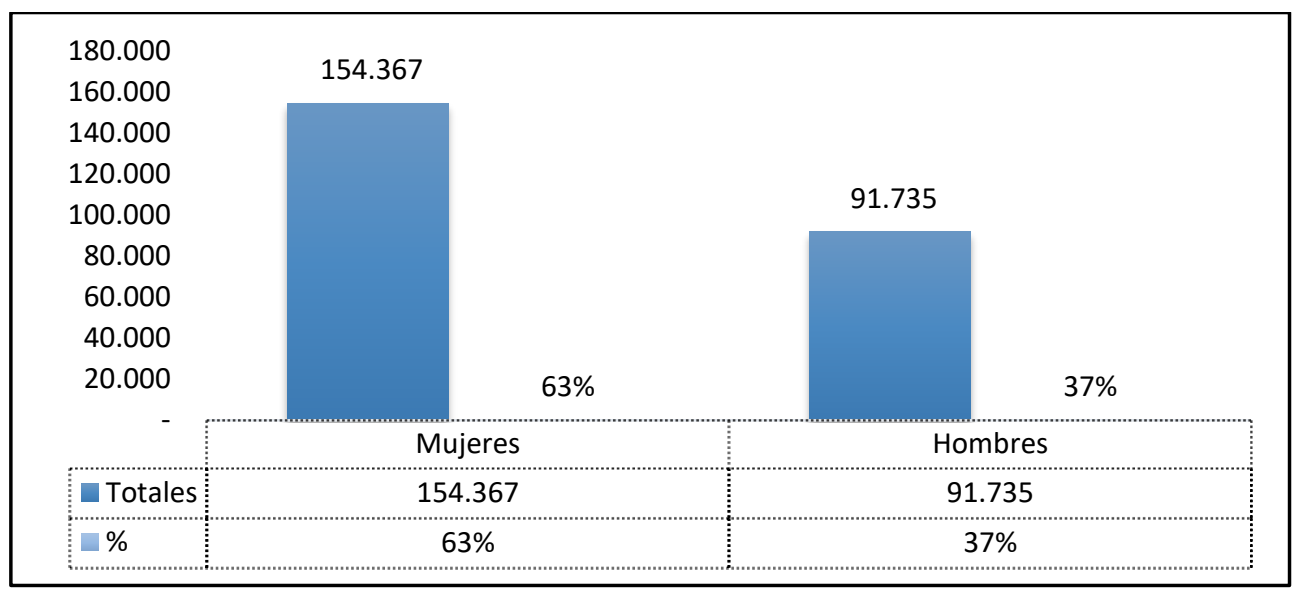

Figura 1. Total de contadores activos a 2018.

Fuente: Elaboración propia a partir de la base de datos de la Junta Central de Contadores (s.f). Recuperado el 3 de septiembre de 2017, de http://www.jcc.gov.co/tramites-y servicios/servicios/sanciones/contadores$\underline{\text { sancionados }}$

A la fecha, el total de profesionales en contaduría pública activos son 246.102 de los cuales 154.367 son mujeres y representan el 63\%; por otra parte, hay registros de 91.735 hombres que representan el 37\% restante. Con base en la lista de sancionados por la Junta Central de Contadores, entre los años 2012-2017, se evidenció que del total de las 504 sanciones impuestas en el periodo objeto de estudio, 87 de estas corresponden a 42 contadores públicos quienes incurrieron en sanciones más de una vez, de los cuales 21 son hombres (sancionados en total 38 veces) y 21 son mujeres (sancionadas en total 49 veces). De estas sanciones impuestas, se detallará puntualmente los resultados obtenidos de cada uno de los ítems contenidos en la lista de sancionados (género, conducta, consecuencia, falta y año de la sanción) como sigue: 


\section{Por género:}

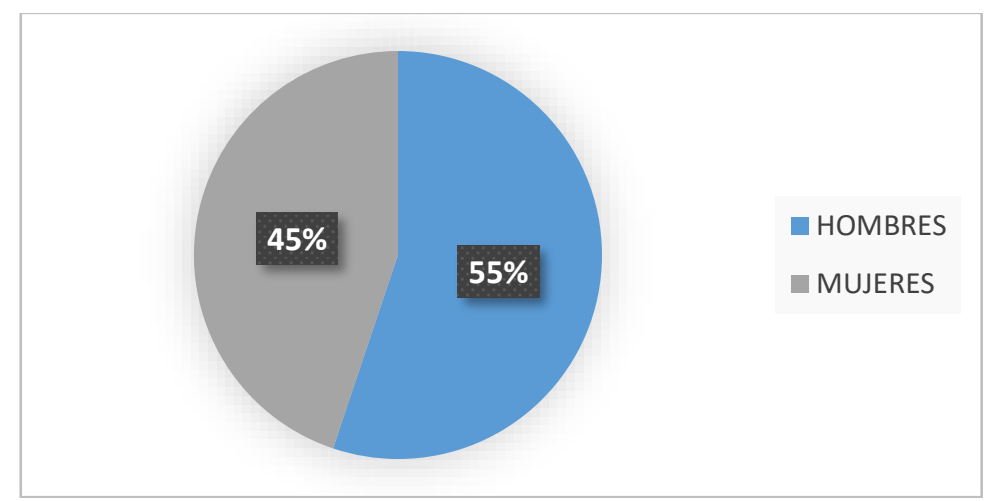

Figura 2. Género de los sancionados

Fuente: Elaboración propia a partir de la base de datos de la Junta Central de Contadores (s.f). Recuperado el 3 de septiembre de 2017, de http://www.jcc.gov.co/tramites-y servicios/servicios/sanciones/contadoressancionados

En primer lugar, al tabular los datos consultados teniendo en cuenta solamente el género, se evidencia que de 417 contadores públicos sancionados en el periodo objeto de estudio, 230 son hombres; es decir, el 55\%. Dicha información, ratifica los resultados de la investigación realizada por Tapia y Orenday (2016, Pág. 241) quienes afirman que "se consideran a los hombres más corruptos que las mujeres; la mayoría de estas últimas es calificada como poco corruptas o corruptas, mientras que los hombres son calificados por la mayoría como corruptos y muy corruptos".

Ahora bien, al observar otros factores como tipo de comportamiento y conducta, se deduce lo siguiente:

\section{Tipo de falta:}

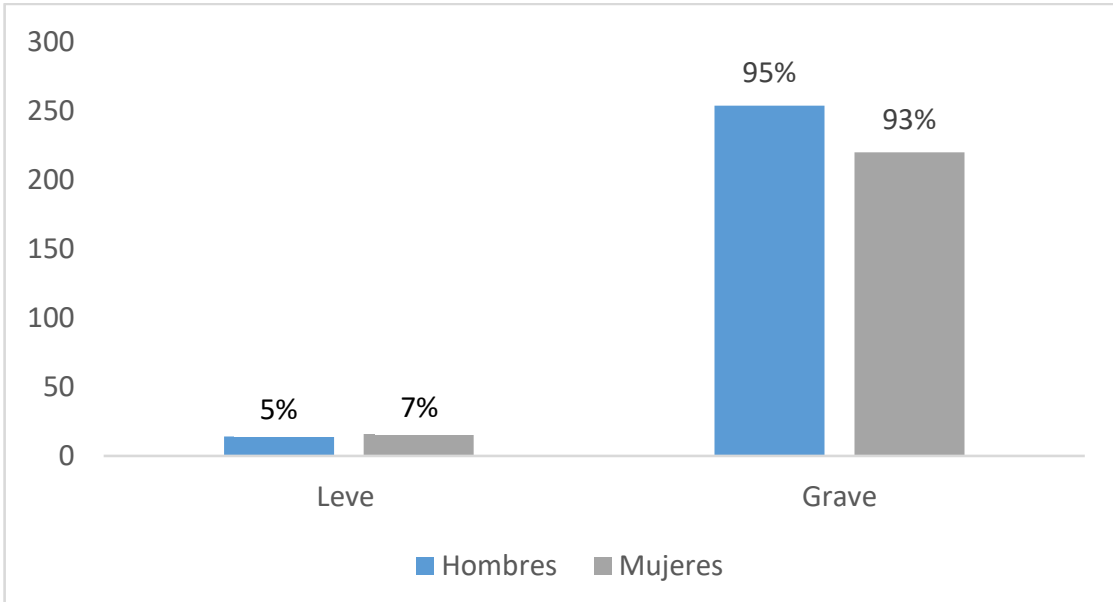

Figura 3. Comportamiento de los sancionados.

Fuente: Elaboración propia a partir de la base de datos de la Junta Central de Contadores (s.f). Recuperado el 3 de septiembre de 2017, de http://www.jcc.gov.co/tramites-y servicios/servicios/sanciones/contadores$\underline{\text { sancionados }}$ 
Las mujeres cometen más actos deshonestos considerados como leves, con 16 casos frente a 14 casos de los hombres. Mientras que en los casos más graves se ven implicados una mayor cantidad de hombres, con 254 casos, en relación con 220 casos de las mujeres. Al parecer, muchos contadores (hombres y mujeres), han olvidado el concepto fundamental de la responsabilidad social, dados los recientes y muy frecuentes casos de corrupción. "La integridad en la información contable exige honestidad y fuerte compromiso con la conducta ética haciendo lo correcto. Para un contador la conducta ética es tan importante como la competencia” (Álvarez, 2002, pág. 158).

Por otro lado, si se considera el tipo de conducta que los guio a cometer acciones fraudulentas, tales como: Dolo "cuando el sujeto disciplinable conoce los hechos constitutivos de la falta disciplinaria, su ilicitud y quiere su realización” (Procuraduría General de la Nación, 2014, pág. 20) o culpa "cuando el sujeto disciplinable incurre en los hechos constitutivos de falta disciplinaria, por la infracción al deber objetivo de cuidado funcionalmente exigible y el sujeto disciplinable debió haberla previsto por ser previsible o habiéndola previsto confió en poder evitarla" (Procuraduría General de la Nación, 2014), se encuentra que:

\section{Conducta:}

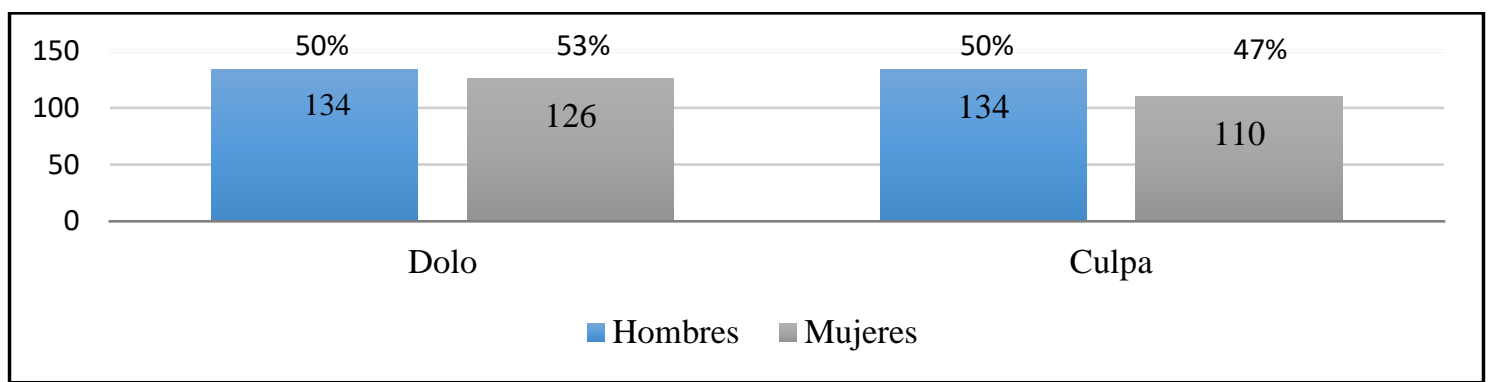

Figura 4. Conducta de los sancionados.

Fuente: Elaboración propia a partir de la base de datos de la Junta Central de Contadores (s.f). Recuperado el 3 de septiembre de 2017, de http://www.jcc.gov.co/tramites-y servicios/servicios/sanciones/contadores-sancionados

Las gráficas anteriores, dejan entrever, que los hombres pueden presentar cualquier conducta sin distinción al presentar 134 casos en ambos ítems. No obstante, las mujeres pese a cometer menores delitos donde se ponga en duda su ética y principios morales, cuando los realizan, es con toda intención y conocimiento, al presentar 126 casos en dolo frente a 110 en culpa. Si se analiza a nivel general, la corrupción es una problemática que afecta el país en todos los ámbitos, esta tiene grave consecuencias, por ejemplo, "la incertidumbre que genera la corrupción por entenebrecer la competencia leal, con sentido humano y social y con proyección de crecimiento, acrecienta costos, resquebraja iniciativas, ahuyenta inversores y distorsiona la política de emprendimiento" (Gómez, 2011, pág. 226).

Finalmente, con base en las causas anteriores, la Junta Central de Contadores impuso las siguientes sanciones: 


\section{Consecuencias:}

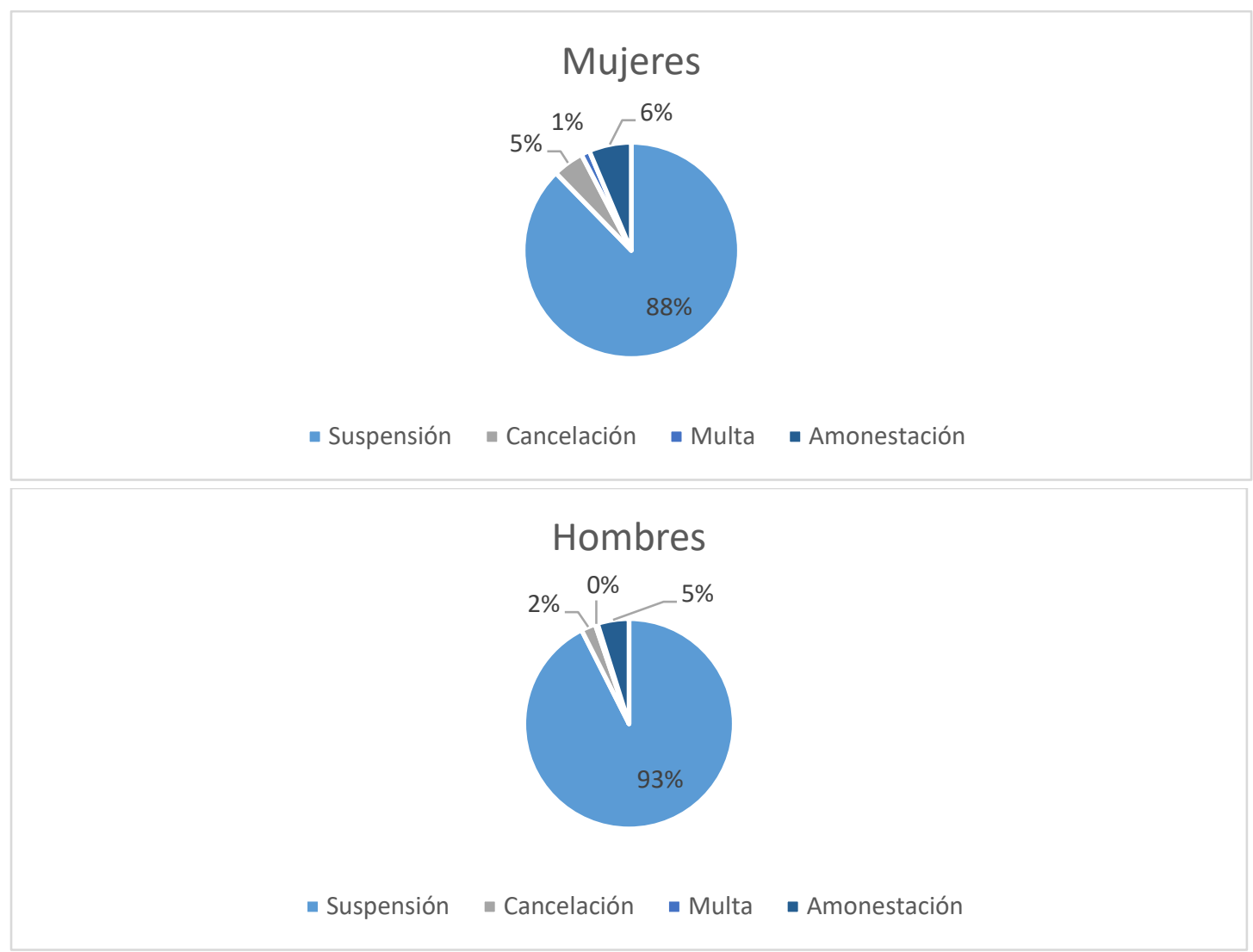

Figura 5. Tipo de Sanciones.

Fuente: Elaboración propia a partir de la base de datos de la Junta Central de Contadores (s.f). Recuperado el 3 de septiembre de 2017, de http://www.jcc.gov.co/tramites-y servicios/servicios/sanciones/contadores-sancionados.

Dando como resultado, que en ambos géneros el porcentaje por multa es casi nulo. Seguido de esto, la cancelación de la tarjeta profesional es más común en mujeres con 11 casos, frente a 6 en hombres, como consecuencia del dolo en las faltas graves. La amonestación es ligeramente más alta en mujeres con 15 casos con respecto a 13 casos en los hombres. Finalmente, la suspensión como medida correctiva más implementada, es más alta en hombres con 248 casos debido a que cometen más delitos, sin considerar si son graves o leves. Las mujeres por su parte registran 207 casos.

Es decir, los resultados arrojan que la diferencia en tipos de sanciones para hombres y mujeres no es amplia, esto debido al ingreso de la mujer a las universidades y a su acceso a cargos altos. Como lo indica (Méndez, 2010) "el factor limitante para que pudieran complementar su conocimiento empírico, y, por ende, liderar desde el inicio en este campo, ha sido el acceso condicionado a la educación" (pág. 92). 


\section{Sanciones por año:}

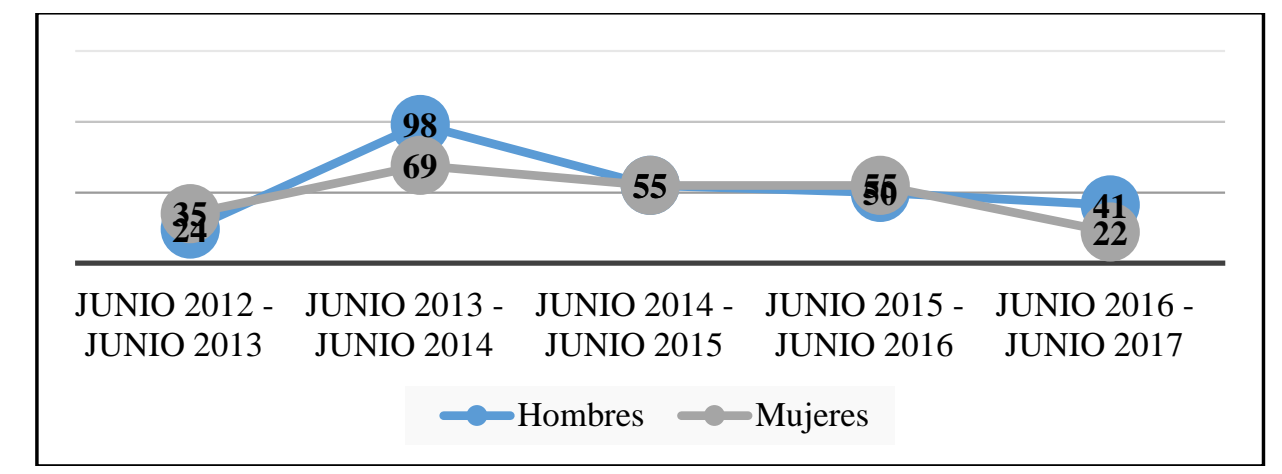

Figura 6. Número de sanciones por año.

Fuente: Elaboración propia a partir de la base de datos de la Junta Central de Contadores (s.f). Recuperado el 3 de septiembre de 2017, de http://www.jcc.gov.co/tramites-y servicios/servicios/sanciones/contadores-sancionados

Cabe agregar, que independientemente del género, entre 2013 y 2014 se cometieron la mayoría de las faltas especialmente en los hombres dado que a pesar de que en los últimos años las mujeres han tenido mayor participación en el mercado laboral, en el periodo diciembre 2013 - febrero 2014 según el DANE en el resumen ejecutivo del mercado laboral por sexo, detalla que las mujeres poseían un mayor nivel de desempleo siendo este un $14 \%$ en comparación con el $7,1 \%$ de los hombres. Dejando evidencia de que la mayor cantidad de sanciones se da en los hombres debido a su mayor participación en el mercado laboral; por otro lado, se evidencia que en las mujeres también aumentan las medidas correctivas, a causa de fuentes alternas de ingresos fraudulentas.

\section{Proceder de los Contadores Públicos en casos concretos de corrupción en Colombia}

Ahora bien, como se ha reiterado a lo largo de esta investigación, Colombia mantiene un índice de corrupción muy alto y actualmente está ubicado en el puesto 96 de 180 países. Desde hace cuatro años, Colombia tiene una calificación de 37, en una escala que va de 0 hasta 100 donde 0 es el nivel más alto de corrupción (Rincón, 2018). Por lo tanto, se procede a explicar tres de los muchos casos que han sucedido, en donde se busca resaltar algunos patrones recurrentes de comportamiento entre los involucrados, dejando de lado su género:

\section{Caso Interbolsa}

Interbolsa, en cabeza de Rodrigo y Tomás Jaramillo, como cualquier otra empresa en Colombia, fue creada bajo la reglamentación legal para constituciones de empresas del Estado Colombiano, registrada en Cámara de Comercio y constituida bajo escritura pública, con la finalidad de proporcionar beneficios a sus clientes en el mercado bursátil y obtener ganancias. Hasta el 2007 la compañía no presentaba fallas legales ni morales en el desarrollo del objeto social de la misma. No obstante, en los años posteriores, cuando Interbolsa era un imperio consolidado, ingresó en el negocio Alessandro Corridori, un inversionista dueño de Fabricato, empresa que recibía millonarios préstamos por parte de la comisionista y que eran cubiertos con una especie de bonos 
de deuda llamados $\operatorname{REPOS}^{5}$ (Donadío, 2013). Es decir, esta empresa comenzó a decaer por la toma de decisiones erradas con respecto a temas de inversión y asociación, que terminó con la quiebra y el escándalo financiero más grande de Colombia, en el cual se vio involucrada la calidad de la profesión contable con la cancelación del registro profesional de la firma de Auditoría Grant Thornton Fast \& ABS Auditores Ltda., quienes prestaban servicios de revisoría fiscal a Interbolsa, así como la suspensión de la tarjeta profesional de la revisoría fiscal designada Ulfany Castillo López y del contador público de Interbolsa Carlos Alberto Posada González por decisión del tribunal disciplinario de la Junta Central de Contadores Públicos como se muestra a continuación:

Tabla 1. Contadores Sancionados. Caso Interbolsa.

\begin{tabular}{|c|c|c|c|c|}
\hline $\begin{array}{c}\text { Razón Social / } \\
\text { Nombre }\end{array}$ & $\begin{array}{c}\text { NIT / Tarjeta } \\
\text { Profesional }\end{array}$ & Sanción & Duración & Conducta \\
\hline $\begin{array}{l}\text { CARLOS } \\
\text { ALBERTO } \\
\text { POSADA } \\
\text { GONZALEZ }\end{array}$ & TP. 70121187 & SUSPENSIÓN & $\begin{array}{l}12 \text { meses } \\
(12 / 12 / 2014- \\
16 / 09 / 2015)\end{array}$ & $\begin{array}{l}\text { El comportamiento que vulnera la ética } \\
\text { profesional se calificó como falta GRAVE a } \\
\text { título de DOLO, como consecuencia del } \\
\text { actuar profesional del Contador Público } \\
\text { CARLOS ALBERTO POSADA } \\
\text { GONZÁLEZ quien, en virtud de su } \\
\text { conocimiento en la actividad contable, } \\
\text { conforme a las normas legales, comprometió } \\
\text { su capacidad calificada, favoreciendo } \\
\text { intereses particulares, en perjuicio de la } \\
\text { confianza pública, del patrimonio de los } \\
\text { particulares y del propio estado. }\end{array}$ \\
\hline $\begin{array}{l}\text { ULFANY } \\
\text { CASTILLO } \\
\text { LOPEZ }\end{array}$ & TP. 52039268 & SUSPENSIÓN & $\begin{array}{l}12 \text { meses } \\
(16 / 12 / 2014- \\
16 / 09 / 2015)\end{array}$ & $\begin{array}{l}\text { El comportamiento que vulnera la ética } \\
\text { profesional se calificó como falta GRAVE a } \\
\text { título de DOLO, como consecuencia del } \\
\text { actuar profesional de la Contadora Pública } \\
\text { ULFANY CASTILLO LÓPEZ quien, en } \\
\text { virtud de su conocimiento en la actividad } \\
\text { contable, conforme a las normas legales, } \\
\text { comprometió su capacidad calificada, } \\
\text { favoreciendo intereses particulares, en } \\
\text { perjuicio de la confianza pública, del } \\
\text { patrimonio de los particulares y del propio } \\
\text { estado. }\end{array}$ \\
\hline
\end{tabular}

Fuente: Listado de Contadores Públicos Sancionados [JCC].

La causa principal de las sanciones impuesta por la Junta Central de Contadores a los profesionales de contaduría pública involucrados fue por ir en contravía a las normas éticas y contables que se deben reflejar en los profesionales, quienes son los que dan fe pública sobre las actividades de las empresas. A demás, se evidenció el incumplimiento de la Ley 43 de 1990, la cual es la Ley que rige la profesión contable en Colombia, debido a que conocían que estaban infringiendo las normas

5 (Donadío, 2013) son operaciones de venta con pacto de recompra, en la cual un inversionista (pasivo) transfiere a otro inversionista (activo) la propiedad de unos valores a cambio de una suma de dinero (precio inicial). El inversionista activo se compromete a devolver los valores al inversionista pasivo el mismo día o en una fecha posterior acordada pagando una suma de dinero que incluye los intereses pactados (precio final). (Citado por Zorro, A. \& Pérez, A., 2016, pág. 40). 
contables y aun así decidieron actuar de manera deshonesta en busca de intereses particulares. Por otro lado, se evidencia que, sin importar su género, los contadores públicos que cometieron estas faltas graves buscaron favorecerse a sí mismos sin importar las repercusiones que tuvieron sus actos. Es por ello que las empresas colombianas deberán implementar la auditoria forense "que servirá como mecanismo de detección y prevención de posibles hechos fraudulentos, permitiendo minimizar los riesgos y mejorar la calidad operativa y financiera de la empresa" (Palacios, 2016, pág. 13).

\section{Desfalco a la DIAN}

Otro caso relevante en la historia de la corrupción de Colombia es el desfalco a la Dirección de Impuestos y Aduanas Nacionales [DIAN] mediante la creación de empresas ficticias o de papel para realizar el hurto de dinero bajo la modalidad de devolución de IVA relacionado a las exportaciones de bienes. Dicho fraude, se generó debido a que una vez las empresas ficticias realizaban su respectiva declaración de IVA en la que se detallaban las devoluciones por exportaciones realizadas,

la Sociedad Intermedia Aduanera (entidad encargada de los trámites de exportación), debía presentar un documento de Exportación (Dex) a la DIAN, para relacionar la mercancía enviada al exterior. Cuando el Dex ingresa a la DIAN para la aprobación debe ser tramitado de manera automática o física, a través del sistema y la verificación de la mercancía existente y la cantidad real por parte de un funcionario de la DIAN; así una vez aprobada y realizada la exportación, la empresa solicitaba la devolución del IVA (Moyano \& Urrego, 2016, pág. 23).

Es decir, para solicitar la devolución debía presentarse un documento el cual era validado por la DIAN, quien determinaba si era aprobada o no de acuerdo con la verificación de la mercancía exportada y de la existencia de los clientes en el exterior. El desfalco a esta entidad se dio en el momento según Moyano y Urrego (2016)

Cuando el Dex de la empresa exportadora era tramitado automáticamente, sin revisar la existencia de la mercancía, ni el respectivo monto, queda aprobado para ser enviada en contenedores a muchos países. Posteriormente, el trámite de devolución del IVA, lo realizaban los funcionarios de la división de fiscalización de la DIAN, donde verificaban solamente a un proveedor (el de mayor monto) de todo el listado que aparece en la solicitud de devolución, al cual le envían un requerimiento ordinario, que respondía de manera verídica con documento (ficticio) que soporta las transacciones con la empresa exportadora. De tal manera se evidenciaba una estructura preparada y dirigida, para que todo se llevará a cabo en un período inferior a 10 días. (pág. 23)

En este desfalco, como en muchos otros casos de corrupción en el país, se vieron involucradas varias personas como lo fueron; contadores públicos (Sandra Liliana Rojas García, Catherine Cano Martínez, Jazmín Bibiana Silva Sánchez, Andrea Bottina Montero y Luz Adriana Matamba Sepúlveda), funcionarios de la DIAN, familiares del actor intelectual del robo y Blanca Jazmín 
Becerra (Actor intelectual). Estas personas recibieron penalización por parte del Tribunal Superior de Justicia y actualmente se encuentran pagando condena por los delitos cometidos. Además, la Junta Central de Contadores públicos a través de su tribunal disciplinario sancionó a varios Contadores públicos como se muestra en la Tabla 2.

La causa de las sanciones a las contadoras mencionadas en la Tabla 2, se dio debido a la certificación y firma de hechos económicos inexistentes teniendo conocimiento de que las devoluciones de IVA que se estaban solicitando no representaban la realidad e iban en contra de las normas éticas y contables de los profesionales colombianos contenidas en la Ley 43 de 1990, el Código de Comercio y demás normas aplicables.

Igualmente, se puede observar que los contadores públicos involucrados en este caso tan reconocido de corrupción en Colombia son particularmente mujeres, quienes decidieron, teniendo conocimiento sobre las implicaciones que acarrearía el cometer este acto, llevar a cabo el desfalco a la DIAN por motivos personales e influencia de los jefes sin tener en cuenta la vulnerabilidad a la fe pública en la profesión contable. Por otro lado, se observa que la señora Jazmín Viviana Silva Sánchez identificada como Contador Público mediante Tarjeta Profesional №52309995, cometió en el mismo caso repetidas violaciones a las normas contables mostrando un desinterés y rebeldía frente a las sanciones en las que había incurrido, lo que conllevo a que el Tribunal Disciplinario de la Junta Central de Contadores [JCC] procediera a la cancelación de su Tarjeta Profesional.

Otro factor importante que se evidenció en las sanciones impuestas a las mujeres contadoras públicas implicadas en el desfalco fue que la mayoría de las suspensiones que les emitió el Tribunal disciplinario de la JCC fueron graves a título de Dolo, es decir que estas Contadoras incurrieron en este desfalco con toda la intención de causar daño a la entidad o personas, además, de que eran conscientes de lo que implicaría el ser descubiertas por los entes reguladores en materia contable. 
Tabla 2. Contadores Sancionados. Desfalco a la DIAN

\begin{tabular}{|c|c|c|c|c|}
\hline $\begin{array}{l}\text { Razón Social } \\
\text { / Nombre }\end{array}$ & $\begin{array}{l}\text { NIT / Tarjeta } \\
\text { Profesional } \\
\end{array}$ & Sanción & Duración & CONDUCTA \\
\hline \multirow{6}{*}{$\begin{array}{l}\text { JAZMIN } \\
\text { VIVIANA } \\
\text { SILVA } \\
\text { SANCHEZ }\end{array}$} & \multirow{6}{*}{ ТР. 52309995} & SUSPENSIÓN & \begin{tabular}{|l|}
12 meses \\
$(13 / 09 / 2012-$ \\
$18 / 12 / 2012)$
\end{tabular} & $\begin{array}{l}\text { Los comportamientos que vulneran la ética profesional se calificaron como graves a título } \\
\text { de culpa, como consecuencia del actuar de la Contadora Pública JAZMÎ́N VIVIANA } \\
\text { SILVA SÁNCHEZ, como revisora fiscal de la sociedad METALES LEO S.A.U. y ahora } \\
\text { METALES LEO S.A.S de la ciudad de Bogotá por cuanto elaboró, certificó y suscribió } \\
\text { formulario de solicitud de devoluciones saldo a favor inexistente para el segundo (2) } \\
\text { bimestre del año 2009, y sobre hechos contrarios a la realidad. }\end{array}$ \\
\hline & & SUSPENSIÓN & \begin{tabular}{|l|}
12 meses \\
$(26 / 09 / 2013-$ \\
$12 / 09 / 2013)$
\end{tabular} & $\begin{array}{l}\text { El comportamiento que vulnera la ética profesional se califica como GRAVE a título de } \\
\text { CULPA, al demostrarse que inobservó las disposiciones normativas en ejercicio de su } \\
\text { profesional como Revisora Fiscal al servicio del contribuyente COMETNORT S.A.S., toda } \\
\text { vez que certifica mediante la DIAN operaciones económicas con datos contables inexactos } \\
\text { y documentación información contraria a la realidad material del contribuyente para el cual } \\
\text { presta sus servicios profesionales para conseguir impuestos descontables inexistentes y por } \\
\text { tanto no procedentes. }\end{array}$ \\
\hline & & SUSPENSIÓN & \begin{tabular}{|l|}
12 meses \\
$(20 / 06 / 2013-$ \\
$16 / 07 / 2013)$
\end{tabular} & $\begin{array}{l}\text { El comportamiento que vulnera la ética profesional se califica como GRAVE a título de } \\
\text { CULPA, como consecuencia del actuar profesional de la Contadora Pública JAZMIN } \\
\text { VIVIANA SILVA SÁNCHEZ, al certificar hechos contrarios a la realidad, toda vez que en } \\
\text { calidad de Revisora Fiscal de la sociedad METALES LEO S.A.S, firmó documentos que } \\
\text { sirvieron de soporte para solicitar ante la Dirección de Impuestos y Aduanas Nacionales } \\
\text { DIAN, la devolución y/o compensación en el tercer bimestre del año 009, la cual resulta } \\
\text { procedente por inexactitud. }\end{array}$ \\
\hline & & SUSPENSIÓN & \begin{tabular}{|l|}
12 meses \\
$(13 / 08 / 2013-$ \\
$08 / 10 / 2013)$
\end{tabular} & $\begin{array}{l}\text { El comportamiento que vulnera la ética profesional se califica como grave a título de } \\
\text { DOLO, como consecuencia del actuar profesional de la contadora pública JAZMIN } \\
\text { VIVIANA SILVA SÁNCHEZ, al demostrarse la intención dirigida a obtener, las } \\
\text { devoluciones del impuesto sobre las ventas del cuarto y sexto bimestre del año gravable } \\
\text { 2010, bajo soportes de operaciones comerciales, certificando documentos contrarios a la } \\
\text { realidad de la empresa continental de CHATARRA S.A.S. }\end{array}$ \\
\hline & & SUSPENSIÓN & \begin{tabular}{|l|}
12 meses \\
$(27 / 03 / 2014-$ \\
$17 / 06 / 2014)$
\end{tabular} & $\begin{array}{l}\text { El comportamiento que vulnera la ética profesional se calificó como falta grave a título } \\
\text { DOLO dada la intención de certificar información contraria a la realidad al emitir } \\
\text { certificaciones contrarias a la realidad de la empresa EXCEDENTES LCM S.A., con el } \\
\text { objeto de obtener por parte del contribuyente. }\end{array}$ \\
\hline & & SUSPENSIÓN & \begin{tabular}{|l|}
12 meses \\
$(08 / 09 / 2014-$ \\
$21 / 04 / 2015)$
\end{tabular} & $\begin{array}{l}\text { El comportamiento que vulnera la ética profesional se calificó como falta GRAVE a título } \\
\text { DOLO, al emitir certificaciones irregulares dirigidas a obtener las devoluciones originadas } \\
\text { por la declaración de IVA correspondiente al } 4^{\circ} \text { bimestre del año gravable } 2009 \text { del } \\
\text { contribuyente COMERCIALIZADORA WRF SAS. }\end{array}$ \\
\hline
\end{tabular}




\begin{tabular}{|c|c|c|c|c|}
\hline & & CANCELACIÓN & $\begin{array}{l}(25 / 02 / 2016- \\
12 / 04 / 2016)\end{array}$ & $\begin{array}{l}\text { El comportamiento que vulnera la ética profesional, desplegado por la investigada se puede } \\
\text { calificar como GRAVE dadas las circunstancias en que cometió la falta, que recae sobre } \\
\text { las cuatro (4) sanciones por suspensión por las que en su momento le fue abierta } \\
\text { investigación disciplinaria, en virtud del ejercicio profesional de Contadora Pública. Hoy } \\
\text { en día, independientemente de que cuenta con seis (6) sanciones, se han cumplido los } \\
\text { requisitos exigidos por la norma, para que este Tribunal imponga la CANCELACIÓN DE } \\
\text { LA INSCRIPCIÓN; dicha situación, por lo tanto no se configura en un agravante de la } \\
\text { responsabilidad, de la aquí investigada; a título de DOLO, por cuanto la profesional en la } \\
\text { ciencia contable tiene la obligación de conocer las responsabilidades éticas, emanadas de } \\
\text { la prestación de los servicios de contaduría y, aun así, como se indicó previamente, la } \\
\text { reincidencia presupone un desconocimiento aireado y rebelde -por lo tanto inteligible y } \\
\text { consciente-, de las normas que debe atender en concordancia con la profesión o cargo que } \\
\text { desempeñe. }\end{array}$ \\
\hline \multirow[t]{2}{*}{$\begin{array}{l}\text { ANDREA } \\
\text { BOTINA } \\
\text { MONTERO }\end{array}$} & \multirow[t]{2}{*}{ TP. 39515622} & SUSPENSIÓN & $\begin{array}{l}12 \text { meses } \\
(13 / 08 / 2013- \\
19 / 12 / 2013)\end{array}$ & $\begin{array}{l}\text { Los comportamientos que vulneran la ética profesional se cometieron como falta grave a } \\
\text { título de dolo, como consecuencia del actuar de la contadora pública ANDREA BOTINA } \\
\text { MONTERO, quien actuó como revisoría fiscal de la sociedad CATEXCO CASA TEXTIL } \\
\text { COLOMBIANA S.A.S. de la ciudad de Bogotá, al demostrarse que firmó la declaración de } \\
\text { impuestos sobre las ventas IVA del segundo bimestre del } 2010 \text { con fecha de presentación } \\
20 \text { de mayo de } 2010 \text {, así como la relación de impuestos descontables y de venta a } \\
\text { comercializadora internacional, documentos en los cuales se consignaron datos contables } \\
\text { inexactos, en cuanto a los proveedores los cuales la administración tributaria demostró que } \\
\text { eran inexistentes. }\end{array}$ \\
\hline & & SUSPENSIÓN & $\begin{array}{l}12 \text { meses } \\
(23 / 04 / 2015- \\
01 / 06 / 2016)\end{array}$ & $\begin{array}{l}\text { El comportamiento que vulnera la ética profesional de la Contadora Pública ANDREA } \\
\text { BOTINA MONTERO se puede calificar como GRAVE a título de DOLO teniendo en } \\
\text { cuenta que, en su condición de revisora fiscal, con conocimiento de su actuar irregular, } \\
\text { otorgó fe pública con su firma de una información que no correspondía a la realidad de las } \\
\text { operaciones realizadas por la usuaria de sus servicios. }\end{array}$ \\
\hline \multirow[b]{2}{*}{$\begin{array}{l}\text { LUZ } \\
\text { ADRIANA } \\
\text { MATAMBA } \\
\text { SEPÚLVEDA }\end{array}$} & \multirow[b]{2}{*}{ ТР. 42010429} & SUSPENSIÓN & $\begin{array}{l}6 \text { meses } \\
(02 / 08 / 2012- \\
21 / 09 / 2012)\end{array}$ & $\begin{array}{l}\text { Los comportamientos que vulneran la ética profesional se cometieron a título de DOLO, } \\
\text { como consecuencia del actuar de la Contadora Pública LUZ ADRIANA MATAMBA } \\
\text { SEPÚLVEDA, por actuar como revisora fiscal en más de cinco (5) sociedades por acciones } \\
\text { en la ciudad de Bogotá D.C., inobservando la prohibición legal del artículo } 215 \text { del Código } \\
\text { de Comercio. }\end{array}$ \\
\hline & & SUSPENSIÓN & $\begin{array}{l}12 \text { meses } \\
(27 / 11 / 2013- \\
07 / 04 / 2014)\end{array}$ & $\begin{array}{l}\text { los comportamientos que vulneran la ética profesional se consideran como falta GRAVE, } \\
\text { A TÍTULO DE DOLO como consecuencia del actuar de la profesional LUZ ADRIANA } \\
\text { MATAMBA SEPULVEDA, como revisora fiscal del contribuyente METALES TATO } \\
\text { S.A.S. de la ciudad de Bogotá, al demostrarse que firmó certificado de relación de IVA } \\
\text { compras y relación de IVA de ventas las cuales fueron soporte en solicitud de devolución } \\
\text { con garantía de saldo a favor originado de impuesto de venta del tercer bimestre de } 2009 \text {, } \\
\text { radicado el } 15 \text { de marzo de 2010, información que la administración tributaria demostró } \\
\text { que eran inexistentes. }\end{array}$ \\
\hline
\end{tabular}




\begin{tabular}{|c|c|c|}
\hline SUSPENSIÓN & \begin{tabular}{|l|}
12 meses \\
$(27 / 11 / 2013-$ \\
$29 / 07 / 2014)$
\end{tabular} & $\begin{array}{l}\text { El comportamiento que vulnera la ética profesional se calificó como grave a título de } \\
\text { DOLO, al demostrarse que inobservó las disposiciones normativas en ejercicio de su } \\
\text { profesión como revisora fiscal al servicio de los contribuyentes ALUMEK LTDA, } \\
\text { identificado con NIT. 900.067.117-6, RENOVADORA ROMAN, identificado con NIT. } \\
\text { 900.249.690-7, ALUMINUM METALES VALENCIA S.A.S., identificado con NIT } \\
\text { 900249851-6, METALS AND RECYCLING identificado con NIT 900.249.660-6, } \\
\text { INTERNACIONAL DE METALES ARBOLEDA S.A.U., identificada con NIT } \\
\text { 900.251.138-9, toda vez que certificó ante la DIAN operaciones económicas con datos } \\
\text { contables inexactos y documentación con información contraria a la realidad material de } \\
\text { los contribuyentes para los cuales prestó sus servicios profesionales para conseguir, } \\
\text { impuestos descontables inexistentes y por tanto no procedentes. }\end{array}$ \\
\hline SUSPENSIÓN & \begin{tabular}{|l|}
12 meses \\
$(10 / 04 / 2014-$ \\
$07 / 07 / 2015)$
\end{tabular} & $\begin{array}{l}\text { El comportamiento que vulnera la ética profesional se cometió como falta GRAVE a título } \\
\text { de DOLO, dada la intención de certificar información contraria a la realidad con el objeto } \\
\text { de obtener un beneficio fiscal inexistente a favor del contribuyente usuario de sus servicios, } \\
\text { emitiendo certificaciones donde se consignaron datos contables inexactos, que no reflejan } \\
\text { la realidad fiscal del contribuyente. }\end{array}$ \\
\hline SUSPENSIÓN & \begin{tabular}{|l|}
12 meses \\
$(29 / 01 / 2015-$ \\
$04 / 01 / 2016)$
\end{tabular} & $\begin{array}{l}\text { El comportamiento que vulnera la ética profesional por parte de la Contadora Pública LUZ } \\
\text { ADRIANA MATAMBA SEPULVEDA se calificó como falta GRAVE a título de DOLO; } \\
\text { en calidad de Revisor Fiscal de la sociedad METALES SANTALIBRADA S.A.S. al } \\
\text { certificar información correspondiente a la solicitud de devolución del impuesto a las ventas } \\
\text { IVA periodo primero y segundo del año gravable 2009, presentada en el mes de febrero de } \\
\text { 2010, no corresponden a la realidad pues las operaciones que realizó con sus proveedores } \\
\text { no son reales, toda vez que la cadena de operaciones se realizó documentalmente y se } \\
\text { demostró que sus mayores proveedores no cuentan con la infraestructura necesaria para } \\
\text { desarrollar tal cantidad de operaciones económicas; de su conocimiento desatendió su deber } \\
\text { profesional al certificar con registros de datos contables inexactos con contenidos que no } \\
\text { corresponden a realidad material del contribuyente para el cual prestó sus servicios. }\end{array}$ \\
\hline
\end{tabular}

Fuente: Listado de Contadores Públicos Sancionados [JCC]. 


\section{Sayco}

Finalmente, entre los casos más sonados de corrupción en empresas colombianas, se encuentra el caso de Sayco y Acinpro, empresas sin ánimo de lucro dedicadas al recaudo y distribución de derechos de autor de compositores colombianos afiliados. Sin embargo, los malos manejos de la compañía en cabeza de la administración desencadenaron en el descubrimiento por parte de las autoridades competentes, la corrupción que se venía presentando dentro de la compañía, durante el 2010 y 2011. Esto se dio debido a que

Los directivos de SAYCO que han ganado sueldos mensuales millonarios no han sido capaces con la organización. Amparados por quienes han sido elegidos en las asambleas, han cambiado el destino de los recursos para comprar edificios, realizar obras, montar oficinas lujosas y cuanta variedad de pensamientos perversos inventaron, para quitarle a muchos compositores los derechos y dejarlos por fuera. (Bejarano, 2015, párrafo 2)

Sin embargo, no sólo la administración de la compañía estaba involucrada en este escándalo, también lo estaba la parte contable y fiscal. En este caso en particular, se vio involucrado el revisor fiscal Jorge Ernesto Sánchez Pérez quien al tener conocimiento de lo que ocurría dentro de la compañía no se pronunció, ni tomó las medidas necesarias frente a las irregularidades que venía presentando la compañía y quien fue sancionado por la Junta Central de Contadores públicos a través de su tribunal disciplinario así:

Tabla 3. Contadores Sancionados. Sayco y Acinpro.

\begin{tabular}{|c|c|c|c|c|}
\hline $\begin{array}{l}\text { Razón Social } \\
\text { / Nombre }\end{array}$ & $\begin{array}{l}\text { NIT / } \\
\text { Tarjeta } \\
\text { Profesional }\end{array}$ & Sanción & Duración & CONDUCTA \\
\hline $\begin{array}{l}\text { JORGE } \\
\text { ERNESTO } \\
\text { SANCHEZ } \\
\text { PEREZ }\end{array}$ & $\begin{array}{l}\text { TP. } \\
19265833\end{array}$ & SUSPENSIÓN & $\begin{array}{l}10 \text { meses } \\
(27 / 11 / 2013- \\
25 / 03 / 2014)\end{array}$ & $\begin{array}{l}\text { Los comportamientos que vulneran la ética } \\
\text { profesional se cometieron por parte del revisor fiscal } \\
\text { Jorge Ernesto Sánchez Pérez, al no pronunciarse, ni } \\
\text { ejercer las medidas pertinentes frente a } \\
\text { irregularidades ocurridas durante los años } 2010 \text { y } \\
2011 \text { al interior de la sociedad de autores y } \\
\text { compositores de Colombia - Sayco, en relación con la } \\
\text { autorización u otorgamiento de anticipos ordinarios y } \\
\text { extraordinarios, sin la debida justificación, y sin } \\
\text { cumplir las disposiciones legales y estatutarias, los } \\
\text { cuales ascendieron a la suma de } \$ 2.410 .544 .000 \text {, así } \\
\text { como celebración irregular de contratos por parte del } \\
\text { gerente general, en relación con trabajos de } \\
\text { remodelación y adecuación de la antigua sede social } \\
\text { de Sayco, en donde se comprometieron mayores } \\
\text { recursos de los que fueron autorizados por la } \\
\text { asamblea general, celebración de contratos por } \\
\text { montos superiores a los que legalmente son } \\
\text { permitidos por estatutos, gastos excesivos en eventos } \\
\text { de homenajes a personal administrativo de Sayco, que } \\
\text { no están contemplados legal ni estatutariamente. }\end{array}$ \\
\hline
\end{tabular}

Fuente: Listado de Contadores Públicos Sancionados [JCC]. 
En definitiva, se puede evidenciar que los casos de corrupción en Colombia, en su mayoría son realizados por altos funcionarios de las empresas, pero debido al alto grado de relevancia del cargo de Contador Público y Revisor Fiscal, estos se ven directa o indirectamente involucrados en estos. De acuerdo con los casos mencionados anteriormente, se puede determinar que los patrones recurrentes a la hora de cometer fraude van vinculados con el triángulo del fraude como se detalla a continuación:

Tabla 4. Patrones recurrentes en fraudes.

\begin{tabular}{|c|c|c|c|}
\hline Triángulo del Fraude & \multicolumn{3}{|c|}{ Casos reales de Corrupción en Colombia } \\
\hline Patrones & Interbolsa & Desfalco a la DIAN & Sayco \\
\hline $\begin{array}{l}\text { Presión. } \\
\text { Manejo constante de las cifras } \\
\text { de la compañía. }\end{array}$ & $\begin{array}{l}\text { Carlos Alberto Posada } \\
\text { González (Contador } \\
\text { Público) favoreció los } \\
\text { intereses tanto personales, } \\
\text { como particulares de la } \\
\text { compañía aun teniendo } \\
\text { conocimiento sobre la } \\
\text { actividad contable. }\end{array}$ & $\begin{array}{l}\text { Las Contadoras Públicas } \\
\text { involucradas en este } \\
\text { escándalo, participaron } \\
\text { certificando registros de } \\
\text { datos contables que } \\
\text { actividades que r no } \\
\text { correspondían a ra } \\
\text { realidad, conociendo que } \\
\text { las empresas a las cuales } \\
\text { estaban certificando eran } \\
\text { ficticias. }\end{array}$ & $\begin{array}{l}\text { Jorge Ernesto Sanchez } \\
\text { Pérez } \quad \text { (Contador } \\
\text { Público) favoreció los } \\
\text { intereses ranto } \\
\text { personales, como } \\
\text { particulares de la } \\
\text { compañía aun teniendo } \\
\text { conocimiento sobre la } \\
\text { actividad contable. }\end{array}$ \\
\hline $\begin{array}{l}\text { Oportunidad. } \\
\text { Ausencia de controles o } \\
\text { controles inefectivos. }\end{array}$ & $\begin{array}{l}\text { Al tratarse de un tema de } \\
\text { personas de alto rango, se } \\
\text { evidencia la ausencia de } \\
\text { controles y segregación } \\
\text { de funciones inadecuada, } \\
\text { dado que nadie a parte de } \\
\text { los implicados conocía } \\
\text { sobre lo sucedido. }\end{array}$ & $\begin{array}{l}\text { Al tratarse de empresas } \\
\text { ficticias y al estar } \\
\text { confabulados además con } \\
\text { funcionarios de la DIAN, } \\
\text { no presentaban controles } \\
\text { que evitaran que se } \\
\text { produjera el desfalco. }\end{array}$ & $\begin{array}{l}\text { Al tratarse de un tema } \\
\text { de personas de alto } \\
\text { rango, se evidencia la } \\
\text { ausencia de controles y } \\
\text { segregación de } \\
\text { funciones inadecuada, } \\
\text { dado que nadie a parte } \\
\text { de los implicados } \\
\text { conocía sobre lo } \\
\text { sucedido. }\end{array}$ \\
\hline $\begin{array}{l}\text { Racionalización. } \\
\text { Convencimiento de que, si } \\
\text { otras personas lo cometen, yo } \\
\text { no soy la excepción }\end{array}$ & $\begin{array}{l}\text { Posee el conocimiento } \\
\text { sobre las irregularidades } \\
\text { en materia contable, el } \\
\text { cual no reporta a las } \\
\text { entidades } \\
\text { correspondientes. }\end{array}$ & $\begin{array}{l}\text { Pensamiento de que sus } \\
\text { actos son éticos en el } \\
\text { ambiente laboral en el } \\
\text { que se encuentran. }\end{array}$ & $\begin{array}{l}\text { Posee el conocimiento } \\
\text { sobre las } \\
\text { irregularidades en } \\
\text { materia contable, el } \\
\text { cual no reporta a las } \\
\text { entidades } \\
\text { correspondientes. }\end{array}$ \\
\hline
\end{tabular}

Fuente: Elaboración propia. 


\section{Conclusiones:}

Los resultados arrojados evidencian que durante los años 2012 - 2017, los casos de corrupción se dieron en igual medida tanto en hombres como en mujeres; lo que daría a entender que la hipótesis propuesta en donde el género es un factor determinante a la hora de cometer actos fraudulentos era una apreciación incorrecta, ya que, de acuerdo con el listado de contadores públicos de la JCC involucrados en temas de fraude durante el periodo objeto de estudio en Colombia, se evidencia que: tanto hombres como mujeres fueron igualmente corruptos, la diferencia es de apenas 5\%, siendo este un porcentaje bajo como para argumentar que los hombres son muy corruptos debido a que "una vez que las mujeres llegan a ocupar puestos de poder son igualmente corruptas que los hombres" (Ramos, Y., 2016, pág. 82). A demás el porcentaje de mujeres es más bajo que el de los hombres dado que "estas no tienen la oportunidad de participar de actos ilegales dominados por hombres" (Ramos, Y., 2016, pág. 82). Incluso, en los casos de corrupción en Colombia se evidencia que los ambos géneros están igualmente implicados en estos.

No obstante, al analizar la información adicional se puede observar que más de la mitad de la población total son mujeres, lo que dejaría a entrever que es una profesión liderada por el género femenino. Pese a esto, si se toman los 417 casos de contadores sancionados reportados en el periodo objeto de estudio, dentro de los cuales 187 son mujeres y 230 son hombres y se contrasta con el número total de profesionales activos que son 246.102, daría como resultado que el $25 \%$ de los hombres han sido sancionados por la junta frente a un $12 \%$ de las mujeres. Dicho análisis, demuestra que a pesar de que la profesión de contaduría tiene más egresadas, los hombres han sido penalizados una mayor cantidad de veces. En este orden de ideas se concluye que el género es un factor determinante en el momento de cometer actos corruptos debido a que "la investigación académica encuentra diferencias tanto psicológicas como cognitivas entre el género" (Chung. J., y Monroe. G., 1998, pág. 267) puesto que "el enfoque de socialización de género sostiene que los hombres y las mujeres responderán de manera diferente al mismo conjunto de condiciones” (Roxas. M., y Stoneback. J., 2004, pág. 150).

De igual manera, en los casos mencionados anteriormente, se puede evidenciar que la corrupción nace a raíz de los vacíos morales y éticos de los profesionales de ambos géneros, en cargos de alta gerencia y que demuestran el afán de multiplicar sus ingresos sin pensar en las consecuencias. Por otro lado, "se observa que el triángulo del fraude, aunque está presente en las empresas, es desconocido entre la mayoría en posiciones gerenciales. Por tal razón, en las empresas no existe un plan de capacitación relacionado al fraude para empleados administrativos” (López \& Sánchez, 2011, pág. 40).

Igualmente, los Contadores Públicos hombres y mujeres, en el momento de cometer actos corruptos presentan patrones recurrentes como lo son: el manejo continuo de las cifras de la compañía, lo que conlleva a que conozcan la cantidad de dinero que entra y sale diariamente 
y la forma de trasladarlo a cuentas personales. Asimismo, otro patrón recurrente es la ausencia de controles o controles muy bajos dentro de una compañía, ya que en muchos casos el contador conoce los procesos y las formas de evadir esos controles sin levantar sospechas. A demás, como tercer patrón recurrente se evidencia el convencimiento de que los actos de corrupción que se están cometiendo son normales, esto debido a los bajos principios éticos. De acuerdo con lo anterior, dichos patrones se encuentran muy relacionados con el triángulo del fraude compuesto por presión, oportunidad y racionalización, dando a entrever que "cuando existe el poder, el individuo busca la oportunidad, pero cuando tiene la oportunidad no racionaliza durante este proceso. Este indicador establece que durante el proceso de fraude y llevarlo a cabo no hay un análisis sobre las consecuencias” (López \& Sánchez, 2011). Ahora bien, si se habla de <presión> el "gerente se ve indirectamente influenciado o se le exige un estilo de vida económico de clase social media alta o alta. Para lograr dicha meta se vale de su poder, a tal grado, que podrá romper con los principios morales" (López \& Sánchez, 2011).

Ahora bien, mencionando el factor <oportunidad>, se evidencia que "el ejecutivo gerencial utiliza su control sobre recursos y personas, tomando riesgos aun sabiendo que, en caso adverso, posiblemente no tenga apoyo legal y se debe a que siempre tendrá la oportunidad de transferir las faltas a sus subalternos” (López \& Sánchez, 2011) Finalmente, se utiliza la <racionalización> "valiéndose de la confianza de los inversores o dueños, para tener cierta autonomía sobre las decisiones y recursos. Conociendo los puntos vulnerables en los negocios, pueden tomar muchas decisiones y con una orden a subalternos pueden ejecutarlas". Sin embargo, cabe destacar que según Wainstein (2003) "Las fuentes de corrupción, si bien son numerosas, se originan principalmente en aquellos países con un nivel de pobreza alto o relativamente alto". Y claramente, Colombia está catalogado como uno de los países con mayores índices de corrupción del mundo.

Finalmente, cabe resaltar que muchas instituciones educativas pecan con el hecho de solamente transmitir información vacía y conocimientos teóricos, sin entender, que la raíz del problema se encuentra en la relación que tiene el contador con su trabajo; es decir, que el profesional trabaje únicamente en función de la empresa donde presta sus servicios, y omita la responsabilidad social que tiene con la sociedad en general, de presentar la información que plasme la verdadera situación financiera (Contreras \& Arango, 2010).

\section{Referencias bibliográficas:}

Acosta, M. G. Patiño, R. A. Valero, G. M. \& Díaz, M. A. (2015). Las problemáticas de género: una introducción para su aplicación en estudios de contabilidad. Revista Activos. 13-(25), 33-72.

Aguilar, H. (1996). El fraude en las organizaciones. Contaduría Universidad de Antioquia. 28, 195-208. 
Álvarez, M. C. (2002). El Contador Público y su responsabilidad social. Contaduría. (41), 145-164.

Arboleda, A. A. (2015). El fraude corporativo en la empresa privada en Colombia. Universidad Militar Nueva Granada. Recuperado el 30 de Agosto de 2017, de http://repository.unimilitar.edu.co/bitstream/10654/7013/1/EL\%20FRAUDE\%20C ORPORATIVO\%20EN\%20LA\%20EMPRESA\%20PRIVADA\%20EN\%20COLO MBIA.pdf

Ariño, M. D., Tomás, C., Eguiluz, M., Samitier, M. L., Oliveros, T., Yago, T., Magallón, R. (2011). ¿Se puede evaluar la perspectiva de género en los proyectos de investigación? Gaceta sanitaria, 2-(25), 146-150.

Bejarano, F. A. (2015). A SAYCO se la comió la corrupción. Recuperado el 2 de julio de 2018, de http://www.las2orillas.co/sayco-se-la-comio-la-corrupcion/

Calatrava, J. (2002). Mujer y desarrollo rural en la globalización: de los proyectos asistenciales a la planificación de género. Información Comercial Española, ICE: Revista de Economía, (803), 73-90.

Caruso, M. V. (2009). El concepto de corrupción: Su evolución hacia un nuevo delito de fraude en el deporte como forma de corrupción en el sector privado. Nueva época $(9)$, 145-172.

Chung, J., \& Monroe, G. (1998). Gender differences in information processing: An empirical test of the hypothesis-confirming strategy in an audit context. Accounting and finance. 38, 265-279.

Contreras, C., \& Arango, D. E. (2010). La ética profesional de un Contador público. Apuntes contables, (14), 201-215.

DANE. Mercado laboral según sexo. Recuperado el 24 de septiembre de 2018, de https://www.dane.gov.co/files/investigaciones/boletines/ech/ech_genero/re_sexo_di c_feb14.pdf

Decreto 410 (1971). Diario oficial N 33339. Por el cual se expide el Código de Comercio. Bogotá D. E., Colombia, 27 de marzo de 1971.

Donadío, A. (2013). El cartel de Interbolsa. Crónica de una estafa financiera. Sílaba. Bogotá. Pág. 1-175.

Junta Central de Contadores. Listado de Contadores Públicos sancionados. Recuperado el 3 de Septiembre de 2017, de http://www.jcc.gov.co/tramites-y servicios/servicios/sanciones/contadores-sancionados 
Junta Central de Contadores. Funciones. Recuperado el 09 de Diciembre de 2018, de http://www.jcc.gov.co/jcc/organizacion/organizacion-de-la-uae.

Gamarra, J. R. (2006). Pobreza, corrupción y participación política: una revisión para el caso colombiano. Documentos de Trabajo sobre Economía Regional. 70, 1692-3715.

Gómez, D. P. (2011). El pacto global de las naciones unidas: sobre la responsabilidad social, la anticorrupción y la seguridad. Revista Prolegómenos - Derechos y Valores. XIV(28), 217-231.

Gómez, D. P. (2014). Corrupción y colusión: asuntos del sector empresarial en Colombia. Revista Prolegómenos - Derechos y Valores. 17-(33), 43-56.

IFAC. 2018 Handbook of the international code of ethics for professional Accountants. Recuperado el 9 de diciembre de 2018, de https://www.ifac.org/publicationsresources/2018-handbook-international-code-ethics-professional-accountants.

Ley 43. (1990). Por la cual se adiciona la Ley 145 de 1960, reglamentaria de la profesión de Contador Público y se dictan otras disposiciones. Bogotá D.E. Colombia, 13 de diciembre de 1990.López, W., \& Sánchez, J. (2011). El triángulo del fraude y sus efectos sobre la integridad laboral. Canales de estudios económicos y empresariales, XXI, 39-57.

López, W., \& Sánchez, J. (2011). El triángulo del fraude y sus efectos sobre la integridad laboral. Canales de estudios económicos y empresariales, XXI, 39-57.

Londoño, J. L. (1997). Brechas sociales en Colombia. Revista de la Cepal(61), 19-38.

Méndez, M. T. (2010). De la contabilidad doméstica a la profesionalización contable de las mujeres. ICE Mujeres y Economía (852), 91-98.

Mendoza, J. A. (2009). Detección de fraude en una auditoría de Estados Financieros. Perspectivas(24), 227-242.

Moyano, J. \&Urrego, A. (2016) Amenazas que afectan la deontología del contador público de acuerdo con los casos de Interbolsa s.a., desfalco a la Dian y Sayco s.a., y la aplicación de las salvaguardas del código de ética profesional del contador. Pág. 23

Ochoa, L. M. Zamarra, J. E. \& Castaño, C. E. (2012). Caracterización de las mejores prácticas para la detección de fraude en una auditoría de Estados Financieros: Análisis del caso colombiano. Recuperado el 03 de septiembre de 2017, de Asociación Latinoamericana de Facultades y Escuelas de Contaduría y Administración:

http://www.alafec.unam.mx/docs/asambleas/xiii/ponencias/auditoria/A_04.pdf 
Palacios, A. (2016). La Auditoría Forense en la determinación de riesgos de fraude de la compañía Vestsacer S.A. ULVR. Pág. 13.

Peña, A. E. \& Bastidas, M. C. (2007). La Ética: Fundamento en la Adopción de las Normas Internacionales de Contabilidad. Actualidad Contable FACE. 10-(14), 118-128.

Procuraduría General de la Nación. (2014). Nuevo código disciplinario único. Recuperado el 10 de octubre de $2017, \quad$ de https://www.procuraduria.gov.co/portal/media/file/CDU(1).pdf

Ramos, Y. (2016). La corrupción y sus vínculos con el género, una aproximación al caso mexicano. Revista Mexicana de Análisis Político y Administración Pública. V-(2), 79-106.

Rincón, M. P. (21 de febrero de 2018). Índice de Percepción de la Corrupción 2017: Corrupción, aún sin solución de fondo. Obtenido de Transparencia por Colombia: http://transparenciacolombia.org.co/indice-de-percepcion-de-la-corrupcion-2017corrupcion-aun-sin-solucion-de-fondo/

Roxas, M., \& Stoneback, J. (2004). The importance of gender across cultures in ethical decision-making. Journal of business ethics. 50, 149-165.

Tapia, E., \& Orenday, M. (2016). ¿Son las mujeres menos tolerantes a la corrupción cotidiana que los hombres? Calei-doscopio, 231-254.

Wainstein, M. (2003) La corrupción: Un tema para investigar. Contabilidad y auditoría. 17, $1-74$.

Zorro, A. \& Pérez, A. (2016). La fachada de Interbolsa en la mirada de la auditoría forense. Facultad de Ciencias económicas y contables, Contaduría Pública. 1-80. Recuperado de https://repository.libertadores.edu.co/handle/11371/604. 